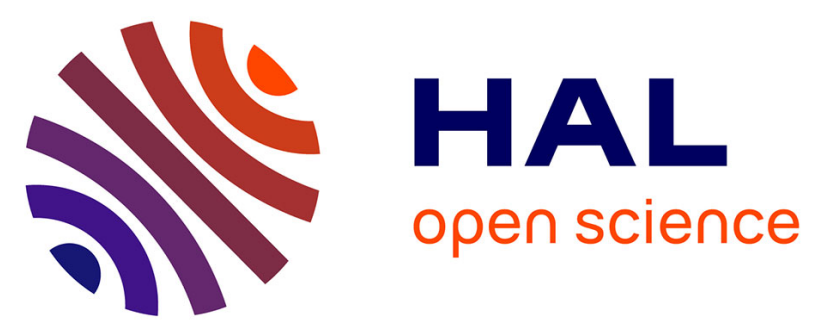

\title{
A METHOD TO CONNECT MATHEMATICS AND SCIENCES USING A COMPUTER ALGEBRA SYSTEM
}

Jean-Paul Becar, Jean-Charles Canonne, Laurent Vermeiren, Fabrice Robert, Eric Cartignies

\section{To cite this version:}

Jean-Paul Becar, Jean-Charles Canonne, Laurent Vermeiren, Fabrice Robert, Eric Cartignies. A METHOD TO CONNECT MATHEMATICS AND SCIENCES USING A COMPUTER ALGEBRA SYSTEM. 9th International Conference on Education and New Learning Technologies (EDULEARN), Jul 2017, Barcelona, Spain. hal-02477769

\section{HAL Id: hal-02477769 \\ https://uphf.hal.science/hal-02477769}

Submitted on 13 Feb 2020

HAL is a multi-disciplinary open access archive for the deposit and dissemination of scientific research documents, whether they are published or not. The documents may come from teaching and research institutions in France or abroad, or from public or private research centers.
L'archive ouverte pluridisciplinaire HAL, est destinée au dépôt et à la diffusion de documents scientifiques de niveau recherche, publiés ou non, émanant des établissements d'enseignement et de recherche français ou étrangers, des laboratoires publics ou privés. 


\title{
A METHOD TO CONNECT MATHEMATICS AND SCIENCES USING A COMPUTER ALGEBRA SYSTEM
}

\author{
Jean-Paul Bécar, Jean-Charles Canonne, Laurent Vermeiren, Fabrice Robert, \\ Eric Cartignies
}

Université de Valenciennes (FRANCE)

\begin{abstract}
The paper presents an experience driven over twenty years in an Institute of Technology. The two first authors are mathematicians, the third one is teaching automatic control and the last is a specialist in digital electronics. The authors have worked, discussed and shared their common teaching experience on how to restore the vanishing student motivation mainly due to the running and efficient technology. As the powerful software in any domain are getting higher, their use in education seem unavoidable. The paper deals with the use of a computer algebra system in a closed connection and applications to the above scientific domains.
\end{abstract}

A computer algebra system is a software that eases the calculation in a way closed to the same as hand calculation. They are used in mathematics and sciences. Their main features are given in the following. A user friendly interface eases the symbolic manipulations. All numerical operations can be done in an arbitrary-precision. The sketch of curves and surfaces is possible in any representation mode. Some systems offers more features first in additional library then included later in the software after users comments and feedback.

For a pedagogical purpose, the well-built on line help is one of the first criterion to choose a computer algebra system rather another one. Nowadays, in higher education, the curriculum of some course includes their natural use in mathematics classrooms.

To make mathematics more attractive, to apply them to different technologies and to do an effective scientific work with pleasure, the authors have adjusted a method that has proved its efficiency for many years. The method is based on the use of a computer algebra system. The paper details this new method. The method is illustrated by three examples in different domains.

The method is now denoted as the DARe method. It holds three major steps. The first one called Discovering is devoted to a direct use of the computer algebraic software to measure its effect in the mathematical background. The second point is called Applying. It focuses on the way to translate the mathematical information in the specific language of the software. The last point called Resolving is mixing the practical acquired knowledge in order to model and solve a scientific problem by the use of the computer algebraic software.

The public concerned with the method is composed of groups of twelve students in the bachelor of technology domain with electrical engineering as speciality. The syllabus is proposing about fifty hours of practical mathematical works. About one thousand students have applied this method. Thanks to their direct comments, discussions and answers to a final questionnaire, the method has been improved since many years. The last release is presented here through some examples taken from automatic control and electronics.

Even if the last step, of the method, "to model a problem ", is rising up the difficulties, the students mention that they are doing rather listening mathematics. The computer algebraic system free them of calculus and prevent them from errors.

The three steps method has been applied with success in a computer science course. It is also extended for experiments to other subjects such as robotics, electronics and mechanics.

Keywords: multidisciplinary, mathematics, computer algebra system, process control.

\section{INTRODUCTION}

The power of numeric and symbolic software is revolutionizing the way to teach sciences. The paper deals with a learning science approach using a computer algebra system. It focuses on a teaching experience that links automation and mathematics. To make mathematics more attractive, to apply 
math to different technologies and to do an effective scientific work with pleasure, the authors have adjusted a method that has proved its efficiency for many years while teaching math with a computer algebra program ([1],[2],[3]). This paper details this original method.

The method is illustrated by the use of a water tank system for a well known teaching platform in process control lab room. A specific questionnaire yields results and discussions on the method. Applied for many years in an institute of technology and recently in a higher school of engineering, the method induces students to be more positive and active when facing new problems. They are doing math rather assisting to math. A teacher quality questionnaire is proving all benefits doing such mathematics and scientific work in a computer algebra software background. The method is now extended for experiments to other subjects such as robotics, electronics, mechanics to increase interdisciplinary.

The starting point of this paper was long discussions between math and automation teachers on the way to motivate students on their syllabus. A couple of years ago those teachers have thought hard on their teaching experience. A particular attention has been put on a special vocabulary used by different subjects of the syllabus.

Students concerned by those domains are second year students in electrical engineering technical course but more recently the method has also been chosen for experimentation in a higher school of engineering in the first year course in mechanics and in hydraulics. All practical mathematics are based on real technological situations [4]. In this paper, a water tank system for teaching platform is chosen as the support of experimentations ([5],[6],[7]).

The paper is organized as follows. Section 2 details the math teaching method in a computer algebraic software background. After a brief review of computer algebraic systems, the paper explains the three parts involved in the method that are discovering, applying and finally resolving a real technological problem. Whatever the technological domain supported in that course, the thread of all works is to write all that happens in order to build a scientific work as well as to make students more active when faced to new problems. This section also presents the system in use for practical works in automation classroom and the required parameters. Section 3 illustrates the teaching method performed in the two contexts and how math and automation can work in synergy. Finally, section 4 presents the results, draws the conclusion on all experiments and explores further developments.

\section{LINKING MATHS AND SCIENCES}

This section shows how math referring to a technical subject can be attractive in a computer algebra system background. To experiment, explain, modify, check, model, and write down all events are some required elements to build a scientific work. The first paragraph is devoted to some computer algebra systems while the second describes the method in use.

\subsection{On Computer Algebra System}

A computer algebra system -CAS in short- is a software program for easy manipulations of formal mathematical expressions. The wide distribution of Mathematica and Maple contributed to make these software packages as popular as possible.

The table 1 shows some main computer algebra systems while a profuse literature is growing in a large scale of scientific domains. All the authors mainly deal with a problem from its mathematical formulation to its computer aided solution and the tools required in that context are further detailed.

Table 1. The main Computer Algebra Systems (with proprietary license in bold font).

\begin{tabular}{|l|l|}
\hline Computer algebra system & Website \\
\hline Maple & www.maplesoft.com \\
\hline Mathematica & www.wolfram.com \\
\hline Mupad & www.mupad.de \\
\hline Scilab & www.scilab.org \\
\hline Sage & www.sagemath.org \\
\hline Maxima & www.ma.utexas.edu \\
\hline
\end{tabular}


This technic applied for many years to students in practical mathematical works was not quite satisfying for the following reasons. The students need at the beginning some main functions on the given subject, they spend too much time learning the tools rather than investigate other directions, they have no reflex to use the software's help. As a result, the authors have focused on a method which is as efficient as possible, as it motivates students to applied math and to the technology and saves time while learning the software and doing a scientific work ([8],[9],[10]). The major part of the efficiency is due to the choice of only one technological application.

\subsection{Using CAS with the DARe method}

The framework is now related to a specific technological problem, e.g. a water tank model forward detailed and its formulation accordingly to the mathematical model established before. All theoretical knowledge in math course as well as in Automation course has been given previously to students within lectures and homework. Here, students have to apply the theoretical skills. The main objective is to do math in connection with a CAS. Modeling a problem to its solution by the use of computer, writing any ideas even fun, sketching the situation, setting equations on paper are the waited skills. For instance, the problem treated here is to solve a nonlinear differential equation and its linearization as known practices in an Automation course by the only use of a CAS. Thus, an instruction guide paper, electronic devices as USB stick or CD or access to the teachers Moodle platform- including a questionnaire - is given to the students at the beginning of a three-hours lab work. The students can arrange themselves either to work alone or with a friend. The latter is mainly preferred. Thus, groups of two students are working on a computer equipped with the Maple software and have to read, explain to each other and fill in a log book. The lab room welcomes up to twelve students.

The short time devoted to the practical work, the initial difficulties to do math drove the teachers to fix the number of new knowledge elements given on students documentation to eight at most for the whole session according to [11]. The road-map inside the instruction guide splits into three roughly equivalent periods denoted as Discovering the tools, Applying the tools and Resolving a problem. That forms the DARe method.

The first period, called Discovering drives students from CAS to math. It represents $25 \%$ of the whole time and of the final assessment too. In order to practice the software, students have to type all helpful functions, observing their effects, modifying parameters if any. During that period students write down the mathematical form of statements and everything that happens including errors, questions to the teacher and their own remarks. At the same time, the teacher discusses on the subject, puts comments in real time on their work, explains instructions if necessary and answers any questions. As all students succeed in this elementary but not simplistic work, this part represents the starting point of the positive attitude and motivation. Based on Pareto's law [12] known as the 80-20 rule it also represents the most useful information to tackle future problems proposed in the last part.

The second period called Applying -25\% of the whole time and of the final mark- guides students from math to CAS. They will both apply the software in well mathematical formulated problems and improve their software knowledge of the given subject. The second period offers as well the opportunity to explore new parameters in built-in functions and to write down everything that occurs.

The last period called Resolving - $50 \%$ of the whole time and of the final mark- puts an end to all previous works and should prove the needs of using CAS for any technical problem. In that part, a problem coming from a real technical situation has to be tackled with. Except for given numerical data, the problem is formulated in current language terms. It means that students should go further, adapt to the problem and thus prove their scientific skills. A final report including all events ends the course and contributes to the student assessment. 
Table 2. The questionnaire for the method DARE.

\begin{tabular}{|l|l|}
\hline Discovering/45 $\mathbf{m i n} / \mathbf{2 5 \%}$ final mark & Smiley \\
\hline Type without errors & \\
\hline Change parameters & \\
\hline Write down notes & \\
\hline Copy/Paste help examples & \\
\hline Give explanation on the First help item & \\
\hline Applying/45 min/25\% final mark & \\
\hline Adapt the syntax & \\
\hline Select the right information from help & \\
\hline Write down notes & \\
\hline Ask questions & \\
\hline Resolving/ $\mathbf{1 h 3 0 m i n / 5 0 \% ~ f i n a l ~ m a r k ~}$ & \\
\hline Discuss with friends and teacher & \\
\hline Write down ideas, sketch, assumptions & \\
\hline Model the problem & \\
\hline Define significant parameters & \\
\hline Set and Solve equations & \\
\hline
\end{tabular}

The questionnaire (see table 2) given to students is filled in front of the students by the teacher while moving on groups. The starting mark is one of the three smileys $: ;(;)$ represents respectively the following states as: needs efforts, to be improved, quite satisfying.

The outlines of a significant example follow.

\subsection{Experimentation}

\subsubsection{The system}

The process control chosen is the classical physical system used in many control laboratories [5], [6] that is to say the double-tank process shown in Fig. 1 whose features are given in table 2.

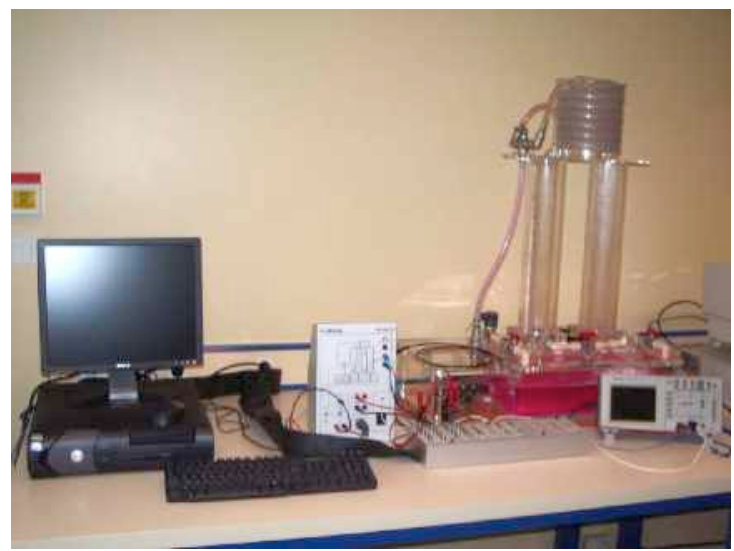

Figure 1. The system.

Several practical works are built around this mock-up. One deals with differential equations and their linearization issued on the single tank process studies. The others based on the two tanks system 
treat on Laplace and $Z$ transformations and pole placements linked with identification, validation and controlling. That are setting the starting point of new applied mathematics work

Table 3. Features of the two tanks system.

\begin{tabular}{|l|l|}
\hline Parameter & Definition \\
\hline $\mathrm{u}(\mathrm{t})$ & input voltage to the pump \\
\hline $\mathrm{q}_{\mathrm{i}}(\mathrm{t})$ & flow through valve $\mathrm{i}, \mathrm{m} / \mathrm{s}^{2}$ \\
\hline $\mathrm{h}_{\mathrm{i}}(\mathrm{t})$ & water level in tank $\mathrm{i}, \mathrm{m}$ \\
\hline $\mathrm{g}$ & acceleration due to gravity, $9.8 \mathrm{~m} / \mathrm{s}^{2}$ \\
\hline$\rho$ & density of liquid, $\mathrm{kg} / \mathrm{m}^{3}$ \\
\hline$\Sigma_{\mathrm{i}}$ & cross-section of tank $\mathrm{i}, \mathrm{m}^{2}$ \\
\hline$\Sigma_{\mathrm{j}}$ & cross-section of exit pipe of tank $\mathrm{j}, \mathrm{m}^{2}$ \\
\hline$P_{\mathrm{a}}$ & atmospheric pressure, $\mathrm{Pa}$ \\
\hline$P_{1}$ & upstream pressure from valve, $\mathrm{Pa}$ \\
\hline$P_{2}$ & downstream pressure from valve, $\mathrm{Pa}$ \\
\hline
\end{tabular}

\subsubsection{The one tank session}

\section{Math background : solving differential equations}

Discovering: During the first 45 minutes of the session students have to try, comment and use help on the main basic Maple instructions concerning differential equations or systems. Three help levels are here possible. First, the features of functions given by the help software, second while copying and pasting some provided examples and finally asking to the teacher.

Question 1: play the following statements and write down any answers and your own useful comments.

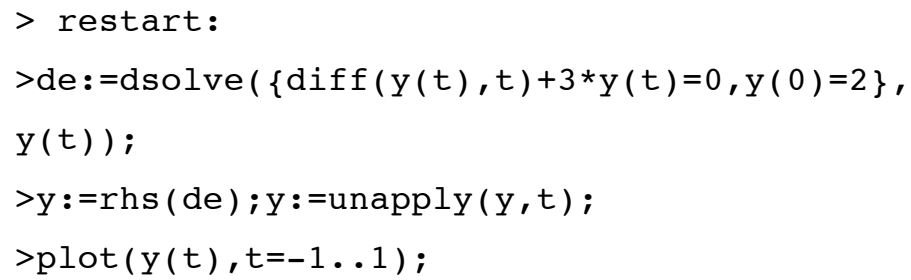

Question 2: Replace the right hand side of the differential equation by each of those following functions.

$$
(2 * t+3) * \exp (4 * t), \quad \sin (5 * t)
$$

Question 3: Replace in question 1 the equation by:

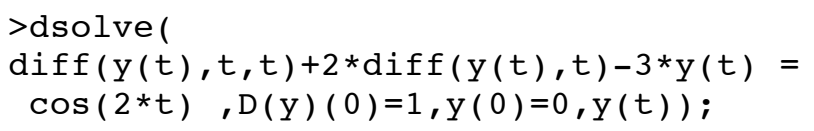

Question 4: Solve the nonlinear differential equation

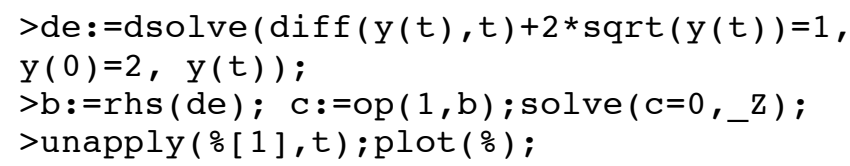

The link is made with automation through concepts such as zero-state response, zero-input response.

Applying: The second 45 minutes session is devoted to solve the nonlinear mathematical model for

$$
\frac{d h}{d t}+\frac{\sigma_{1}}{\Sigma_{1}} \cdot \sqrt{2 g} \sqrt{h_{e q}}=\frac{1}{\rho \cdot \Sigma_{1}}\left(q_{1}(t)-P\left(h(t)-h_{e q}\right)\right)
$$


the single tank with $\mathrm{q}_{1}(\mathrm{t})=$ constant.

Given $h_{e q}$ the height of equilibrium, the equation can be linearized around this value.

With $s(t)=h(t)-h_{e q}$

$$
\frac{d s}{d t}+k_{1} \cdot \sqrt{h_{e q}+s(t)}=\frac{1}{\rho \cdot \Sigma_{1}} \cdot q_{e q}
$$

Students have to solve first the equation (1) using maple software then explore the limits of linearization (2) by sketching the approximate and the exact solutions on a same graph for different values of perturbation.

Resolving: In the last part of the session, students are still more autonomous. They have to model the tank when a proportional controller is used. Two levels of help are proposed for solving the problem. The first element is given by the sketch of the proportional controller. The job consists here in modeling the controller while writing down then solving the differential equation. This also includes the linearization (see Fig. 2).

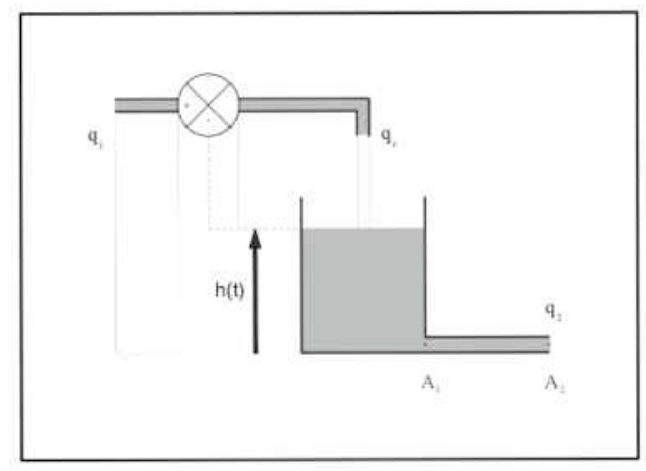

Figure 2. The $P$ controller.

The second level of help could be done by giving the equation of the controller to solve with the CAS. Students had to use different value of the parameter $\mathrm{P}$ and draw response curves. The equation to obtained being:

$$
\frac{d h}{d t}+\frac{\sigma_{1}}{\Sigma_{1}} \cdot \sqrt{2 g} \sqrt{h_{e q}}=\frac{1}{\rho \cdot \Sigma_{1}}\left(q_{1}(t)-P\left(h(t)-h_{e q}\right)\right)
$$

where $\mathrm{P}$ is the proportional gain and the height corresponding to the initial steady state. In this occasion, they have to evaluate the time response of the system using the curve of the solution. They also have to compare the final value of height with the initial one. All lab work long, the teacher supervises the job, fills the questionnaire in real time in front of students and finally gives its final favorite opinion on which is the leader on each group of two students.

\section{RESULTS AND DISCUSSION}

In this section, the results of the recent experiments using the DARe method here are discussed. The questionnaire has been given to the sixty four students in second year of electrical engineering separated in five groups of twelve students. Each group is composed by two or three students working on the subject. To see the trends of the different parts of the DARe method, the boxplot representation has been chosen finally. The boxplot representation on Fig. 3 left shows the results on each part of the questionnaire separately while the boxplot in Fig 3. right provides the final results on the new math working method. The Fig. 3 confirms the basic idea of $D$ point of the method that is to make students more active in front of math. Around $9 \%$ of students succeed at this point. The rest is due the lack of interest for everything in connection with math even with a modern instrument.

The A point of the method reveals $30 \%$ of students have some reticence to swim in the software implying math applications. The Re point proves that even by the use of a CAS, modeling then solving problems is always a difficult subject. Nevertheless, the positive attitude of students all lab work long is a consequence of the marks given in the part RE while writing ideas even far from the right solution. 

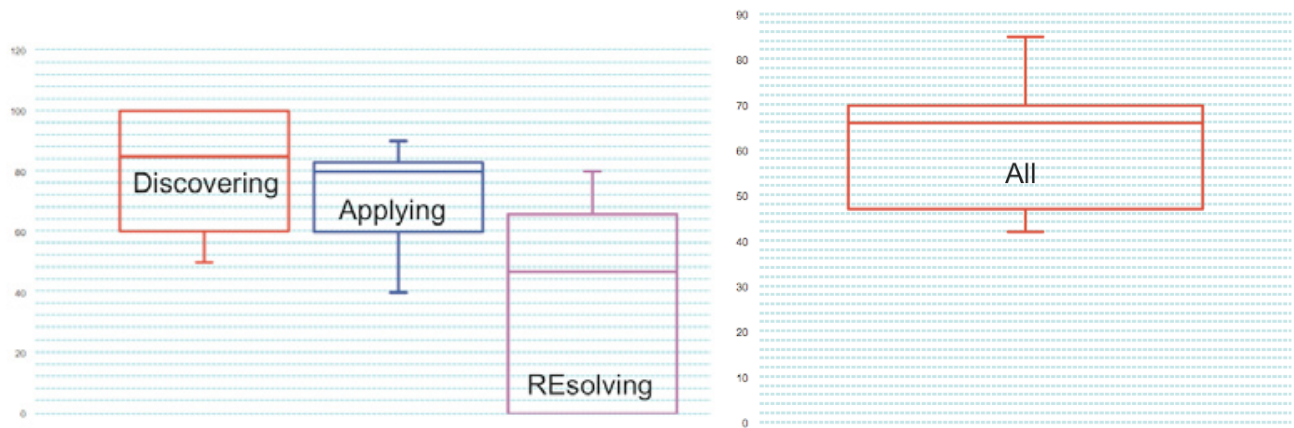

Figure 3. Left the D,A,RE topics skills; Right all topics together.

\section{CONCLUSION}

The authors propose a method to do applied math in connection with process control. Based on a computer algebraic software, the three parts method Discovering. Applying and Resolving has been successfully experimented using Maple software, but can easily be extended other computer algebra programs like Matlab, Scilab, Mupad. By comparison to practicing methods that consist in solving directly problems and discovering the tools on the way, the new method offers to handle the software tools before modelling a problem.

The first part motivates students, the second part wakes up their interest and the last one selects the students. The positive and active student's behavior in front of an application for doing mathematics is one of the important effects. Evaluation in real time with smileys turns the math more funny than cold and classical marks.

The link with automation course offers to students new motivation for both domains. This method has been applied successfully for five years in an electrical engineering course for technicians and also in a higher school of engineering.

Recently, the DARE method model has been applied in the computer science field. The outlines are given below. They fit the same schedule described above. The D-part consists in using a program written in a high level language e.g. $\mathrm{C}, \mathrm{C \#}$, or $\mathrm{C}++$ that runs perfectly, checking the source code that has no comments, filling the source code with personal comments in order to identify the statements. The A-part deals with a defined program where the specification sheet is given and where the source code is only composed of the statement comments without any written statement. The statements will be completed in order to run a program that is fitting the specification sheet. Finally, for the Re-part, a subject is given. The task is to design, comment, check and run the program. The source code must satisfy the rule one line, one statement, one comment.

More recently the DARE method has been experimented in practical lessons in electrical engineering. Further details and results are expected.

\section{AKNOWLEDGEMENTS}

The authors would like to warmly thank the University of Valenciennes and the Institute of Technology for giving the work environment and their colleagues always available for answering questions and sharing their domain skills and contributed to the success.

\section{REFERENCES}

[1] Canonne J.C., Differential systems and transformers with Maple, conference as invited speaker in Satakunta Polytechnic Pori Finland, 2003.

[2] Bécar J.P., cryptography with Maple, conference as invited speaker in Satakunta Polytechnic Pori Finland, 2004, 2005, 2010.

[3] Bécar J.P., Canonne J.C., Vermeiren L., New method to link math and technology : an application to automation, IADAT Journal of Advanced Technology on Education-IJAT-e, Volume 2, Number 4, December 2006, pp 295-297. ISSN 1698-1073. 
[4] Pierce,R., Stacey, K. and Barkatsas. A. (2007). A scale for monitoring students' attitudes to learning mathematics with technology. Computers \& Education, 48, 285-300.

[5] Broida, V. Automatisme (Tome XIV, N3, 1969), 105

[6] Astrom K.J. and Lundh M., 1992, "Lund control program combines theory with hands-on experience ", IEEE Contrl. Syst. Mag., Vol. 12, No 3, pp. 22-30.

[7] Astrom K.J. and Ostberg A.-B., 1986, "A teaching laboratory for process control", IEEE Contrl. Syst. Mag. , Vol. 6, No 3, pp. 37-42.

[8] Cabezas J., Roanes-Lozano E., Rodriguez-Monino Badajoz I.E.S., Do Computer Algebra Systems Change the Order in Which we Should Teach Mathematics? Proceedings of the Third International DERIVE/TI-92 Conference, 1998

[9] Galan Garcia J.L., Galan Garcia M.A., Galvez Galiano A., Jimenez Prieto, A.J, Padilla Dominguez Y., Rodriguez Cielos P.,Computer Algebra Systems: A basic tool for teaching Mathematics in Engineering, Formatex 2005.

[10] Guyer T., Computer Algebra Systems as the Mathematics Teaching Tool ,World Applied Sciences Journal 3 (1): 132-139, 2008 ISSN 1818-4952 @ IDOSI Publications, 2008.

[11] Miller, G. A., The magical number seven, plus or minus two: Some limits on our capacity for processing information, Psychological Review, vol. 63, no 2, 1956, p. 81-97.

[12] Pareto, Vilfredo; Page, Alfred N. (1971), Translation of Manuale di economia politica ("Manual of political economy"), A.M. Kelley, ISBN 9780678008812. 